\title{
PRONE VENTILATION FOR SEVERE ARDS IN A PERIOPERATIVE CAESAREAN PATIENT
}

\author{
Biju Chandrasekharan Nair1, Mohammed Zuhail Kizhakka Peediyakkal², Aswathy Thazhakottuvalappil3, Shibu Saseendran ${ }^{4}$ \\ Malini Tamilarasan ${ }^{5}$
}

${ }^{1}$ Consultant, Department of Critical Care, SUT Hospital, Pattom, Trivandrum. ${ }^{2}$ Consultant, Department of Critical Care, SUT Hospital, Pattom, Trivandrum. ${ }^{3}$ Associate Consultant, Department of Critical Care and Pulmonology, SUT Hospital, Pattom, Trivandrum. ${ }^{4}$ Senior Resident, SUT Hospital, Pattom, Trivandrum.

5 Senior Resident, SUT Hospital, Pattom, Trivandrum.

HOW TO CITE THIS ARTICLE: Nair BC, Peediyakkal MZK, Thazhakottuvalappil A, et al. Prone ventilation for severe ARDS in a perioperative caesarean patient. J. Evolution Med. Dent. Sci. 2017;6(93):6791-6793, DOI: 10.14260/jemds/2017/1469

\section{PRESENTATION OF CASE}

A 33-year-old pregnant female at 30 weeks gestation was referred from another hospital with fever, rhinitis, productive cough, progressive dyspnoea and myalgia of 1 week duration. Her past history was unremarkable except for a history of abortion and congenital scoliosis.

She was conscious, oriented, tachycardic [HR 140/min], BP of $120-70 \mathrm{mmHg}$, in respiratory distress [Tachypnoeic with a RR of 40/min, room air SpO2 52\% and had B/L crepitations].

She was started on NIV. Her ABG revealed respiratory acidosis with severe hypoxia (7.30/ 48/ 35/ 22). Chest x-ray showed bilateral non-homogenous opacities. A provisional diagnosis of severe ARDS due to probable viral pneumonia was made. She was intubated and mechanically ventilated [PCV, $\mathrm{FiO}_{2}$ 1.0, RR 24, PEEP 20]. Treatment was started with empirical antibiotics (Meropenem, linezolid, azithromycin), antiviral (Oseltamivir), steroids for foetal lung maturity and other supportive medications.

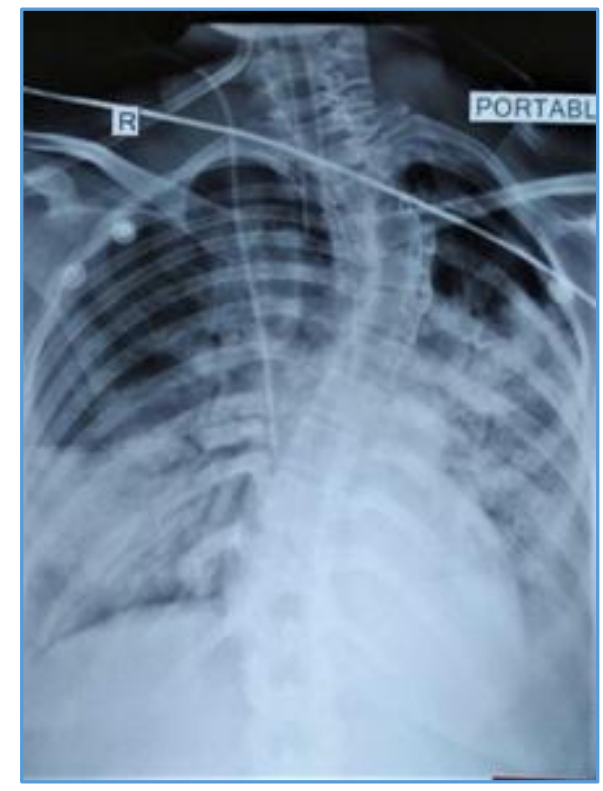

'Financial or Other Competing Interest': None.

Submission 23-10-2017, Peer Review 21-11-2017,

Acceptance 27-11-2017, Published 11-12-2017.

Corresponding Author:

Dr. Biju Chandrasekharan Nair

Department of Critical Care,

SUT Hospital, Pattom,

Trivandrum.

E-mail: sank76@gmail.com

DOI: $10.14260 /$ jemds $/ 2017 / 1469$

\section{(c) $($ ) $\ominus$}

For further management, she was shifted to Multidisciplinary-ICU. A repeat ABG sample was suggestive of worsening Respiratory acidosis (7.20/56/ 55/ 20).

FH was not audible initially, but was confirmed with ultrasound by the obstetrician. As there was a suspicion of H1N1 infection, she was nursed in isolation room with necessary precautions by the attending staff in left lateral position.

Mechanical ventilation was difficult with peak pressures going beyond $40 \mathrm{~cm}$ of $\mathrm{H} 2 \mathrm{O}$. As worsening hypoxia could jeopardise adequate foetal oxygenation, emergency caesarean section was planned. LSCS was done in the ICU as transportation on high ventilator settings posed the risk of desaturation and cardiac arrest. Sedation was deepened with propofol and fentanyl. Atracurium infusion was continued for muscle relaxation. Immediately, after delivery baby was intubated due to respiratory depression and transferred to neonatal ICU.

After caesarean section, the plateau pressures and tidal volume improved. However, there was inadequate improvement in oxygenation. Hence, prone ventilation was implemented. Proning was done within 2 hrs. after LSCS with all precautions. Patient was fully sedated, paralysed and proned for 16 hours continuously on Day 1. CT thorax was deferred in view of risk in transportation with high PEEP and $\mathrm{FiO}_{2}$. After 16 hrs. of prone ventilation with $\mathrm{FiO}_{2}$ 8.0, PEEP 20 there was marginal improvement in oxygenation $\left[\mathrm{PaO}_{2}-69\right]$. On Day 2, there was clinical and radiological worsening. Patient was again proned for $20 \mathrm{hrs}$. and ventilated with $\mathrm{FiO}_{2}$ 1, PEEP 24. Patient was made supine after $20 \mathrm{hrs}$. with an $\mathrm{FiO}_{2}$ of 0.6 and a PEEP of 16 . There was improvement in oxygenation after proning $\left[\mathrm{PaO}_{2}\right.$ - 98]. On Day 4, PEEP was further reduced and muscle relaxants were discontinued. The patient was maintained on sedation with a RAAS score of -1 on PCV mode with $0.5 \mathrm{FiO}_{2}$ and PEEP of 8 . Due to thick secretions and repeated endotracheal tube blockade, a tracheostomy was done on Day 8. By Day 12, the secretions decreased and the patient improved significantly. The patient was weaned off from ventilator to a thermovent $\mathrm{T}$ piece on Day 16. Patient was shifted to room on Day 18 with tracheostomy tube. The tracheostomy stoma was closed on Day 20, and patient and baby was discharged on Day 27.

\section{DISCUSSION}

Acute respiratory distress syndrome (ARDS) is characterised by severe hypoxaemia of acute onset, decreased lung compliance, reduced lung volumes and radiologically bilateral diffuse infiltrates.[1,2] The Berlin definition stratified the patients with ARDS into three categories, namely mild $\left(\mathrm{PaO}_{2} / \mathrm{FiO}_{2} \leq 300 \mathrm{mmHg}\right.$ with PEEP or CPAP $\geq 5 \mathrm{~cm} \mathrm{H} \mathrm{H}_{2} \mathrm{O}$; 
moderate $\left(\mathrm{PaO}_{2} / \mathrm{FiO}_{2} \leq 200 \mathrm{mmHg}\right.$ with PEEP $\left.\geq 5 \mathrm{~cm} / \mathrm{H} 20\right)$; and severe $\left(\mathrm{PaO}_{2} / \mathrm{FiO}_{2} \leq 100 \mathrm{mmHg}\right.$ with PEEP $>5$ $\mathrm{cm} / \mathrm{H} 20) .{ }^{[3]}$ ARDS is a high incidence phenomenon in the field of intensive care. According to the study by Bellany et al, the period prevalence of ARDS was $10.4 \%$ and the syndrome appeared to be both under-recognised and undertreated and was associated with a high mortality rate of $46 \%$ for those with severe ARDS. ${ }^{[4]}$ Considering the disease relevance in the context of intensive care, clinical diagnosis and the adoption of early therapeutic interventions (specially the use of protective ventilator strategies) are determinants for reducing morbidity and increasing patient's survival.[5]

Ventilatory support is considered the cornerstone of ARDS treatment. The goals of mechanical ventilation for ARDS patients are to minimise iatrogenic lung injury [ventilator-induced lung injury (VILI)], while providing acceptable oxygenation and carbon dioxide $\left(\mathrm{CO}_{2}\right)$ clearance. Numerous studies provided clear evidence of large mortality benefit when patients with ARDS were ventilated with a lungprotective strategy- Avoidance of alveolar overdistension using tidal volumes of $6 \mathrm{~mL} / \mathrm{kg}$ predicted body weight with plateau pressures $\leq 30 \mathrm{~cm} \mathrm{H}_{2} \mathrm{O}$, and allowing a low $\mathrm{pH}$ in order to achieve these targets.[6,7]

In patients with severe ARDS $\left(\mathrm{PaO}_{2} / \mathrm{FiO}_{2} \leq 100 \mathrm{mmHg}\right)$, the use of ventilation in the prone position should be considered. Conceptually, prone position ventilation may result in a more uniform distribution of lung stress and strain. By adopting prone position for ventilation, a significant improvement in oxygenation is seen due to the decreased atelectasis, redistribution of $V / Q$, changes in the position and mechanics of diaphragm and a consequent reduction of the gravitational gradient of pleural pressures. Placing patients in the prone position for a portion of time each day during mechanical ventilation was first suggested in 1974.[8] But early randomised controlled trials for prone positioning did not show reductions in mortality. However, these trials included patients with mild ARDS, the duration of prone positioning each day was short and protective lung ventilation (low tidal volumes) was not used.[9,10] A subsequent meta-analysis suggested that prone positioning reduces mortality among patients with severe hypoxaemia.[11] The recently conducted PROSEVA trial also suggested a reduction in mortality in severe ARDS patients who were proned early in the disease process for a longer period of time each day.[12]

The early use of prone position during ventilatory support in patients with severe ARDS on lung protective ventilation with high PEEP levels is associated with the best physiological response of collapsed alveolar units, as maximum alveolar recruitment can be achieved during the initial phase of disease.[13,14] Mortality reduction is related to the improvement in gas exchange and respiratory mechanics. There is also reduction in complications as VILI due to the homogenisation of stress and tension on the pulmonary parenchyma, thus allowing a reduction in $\mathrm{FiO}_{2}$ values and lower airway pressure to obtain adequate oxygenation.[15,16] A recent systematic review and meta-analysis concluded that apart from low tidal volumes with $\mathrm{FiO}_{2}$-guided high PEEP, prone ventilation is potentially the best adjunctive for ventilatory support in terms of improved survival in patients with moderate or severe ARDS.[17] The fact that prone ventilation improves oxygenation and reduces mortality without any special equipment suggests that all patients with severe hypoxaemia should be given a trial of prone ventilation, if there are no contraindications. The recently conducted retrospective multicentre SOPRONADONF study also concluded that prone ventilation of ARDS patients after abdominal surgery was not associated with an increased rate of surgical complications.[18]

Although, low tidal volume is an important determinant of mortality reduction, it has been shown that reductions in tidal volume or increases in PEEP are beneficial only if associated with a driving pressure (plateau pressure- PEEP) lower than $16 \mathrm{~cm} \mathrm{H}_{2} \mathrm{O}$. Driving pressure is the main variable determining the best prognosis for the mortality outcome in patients with moderate or severe ARDS.[19]

Thus, the available scientific evidence suggests that early combination of using protective ventilatory strategy with a sustained driving pressure of less than $16 \mathrm{~cm} \mathrm{H}_{2} \mathrm{O}$ and prone positioning for periods of 16 to 20 hours in patients with severe acute respiratory distress syndrome results in benefits on mortality reduction [20] and postoperative status should not deter intensivists from proning a patient with severe ARDS.

\section{REFERENCES}

[1] Pelosi P, Brazzi L, Gattinoni L. Prone position in acute respiratory distress syndrome. Eur Respir J 2002;20(4):1017-28.

[2] Barbas CS, Isola AM, Caser EB. What is the future of acute respiratory distress syndrome after the Berlin definition? Curr Opin Crit Care 2014;20(1):10-6.

[3] ARDS Definition Task Force, Ranieri VM, Rubenfeld GD, et al. Acute respiratory distress syndrome: the Berlin definition. JAMA 2012;307(23):2526-33.

[4] Bellani G, Laffey JG, Pham T, et al. Epidemiology, patterns of care, and mortality for patients with acute respiratory distress syndrome in intensive care units in 50 countries. JAMA 2016;315(8):788-800.

[5] Papazian L, Forel JM, Gacouin A, et al. Neuromuscular blockers in early acute respiratory distress syndrome. N Engl J Med 2010;363(12):1107-16.

[6] Acute Respiratory Distress Syndrome Network, Brower RG, Matthay MA, et al. Ventilation with lower tidal volumes as compared with traditional tidal volumes for acute lung injury and the acute respiratory distress syndrome. $\mathrm{N}$ Engl J Med 2000;342(18):1301-8.

[7] Putensen C, Theuerkauf N, Zinserling J, et al. Metaanalysis: ventilation strategies and outcomes of the acute respiratory distress syndrome and acute lung injury. Ann Intern Med 2009;151(8):566-76.

[8] Bryan AC. Conference on the scientific basis of respiratory therapy. Pulmonary physiotherapy in the pediatric age group. Comments of a devil's advocate. Am Rev Respir Dis 1974;110(6 Pt 2):143-4.

[9] Gattinoni L, Tognoni G, Pesenti A, et al. Effect of prone positioning on the survival of patients with acute respiratory failure. N Engl J Med 2001;345(8):568-73.

[10] Guerin C, Gaillard S, Lemasson S, et al. Effects of systematic prone positioning in hypoxemic acute respiratory failure: a randomized controlled trial. JAMA 2004;292(19):2379-87. 
[11] Sud S, Friedrich JO, Taccone P, et al. Prone ventilation reduces mortality in patients with acute respiratory failure and severe hypoxemia: systematic review and meta-analysis. Intensive Care Med 2010;36(4):585-99.

[12] Guérin C, Reignier J, Richard JC, et al. Prone positioning in severe acute respiratory distress syndrome. N Engl J Med 2013;368(23):2159-68.

[13] $\mathrm{Hu}$ SL, He HL, Pan C, et al. The effect of prone positioning on mortality in patients with acute respiratory distress syndrome: a meta-analysis of randomized controlled trials. Crit Care 2014;18(3):R109.

[14] Mora-Arteaga JA, Bernal-Ramírez OJ, Rodríguez SJ. The effects of prone position ventilation in patients with acute respiratory distress syndrome: a systematic review and meta-analysis. Med Intensiva 2015;39(6):359-72.

[15] Koulouras V, Papathanakos G, Papathanasiou A, et al. Efficacy of prone position in acute respiratory distress syndrome patients: a pathophysiology-based review. World J Crit Care Med 2016;5(2):121-36.
[16] Gattinoni L, Pesenti A, Carlesso E. Body position changes redistribute lung computed-tomographic density in patients with acute respiratory failure: impact and clinical fallout through the following 20 years. Int Care Med 2013;39(11):1909-15.

[17] Wang $C$, Wang $X$, Chi $C$, et al. Lung ventilation strategies for acute respiratory distress syndrome: a systematic review and network meta-analysis. Sci Rep 2016;6:22855.

[18] Gaudry S, Tuffet S, Lukaszewicz AC, et al. Prone positioning in acute respiratory distress syndrome after abdominal surgery: a multicenter retrospective study SAPRONADONF (Study of Ards and PRONe position After abDOmiNal surgery in France). Ann Intensive Care 2017;7(1):21.

[19] Amato MB, Meade MO, Slutsky AS, et al. Driving pressure and survival in the acute respiratory distress syndrome. N Engl J Med 2015;372(8):747-55.

[20] Dalmedico MM, Salas D, Oliveira AM, et al. Efficacy of prone position in acute respiratory distress syndrome: overview of systematic reviews. Rev Esc Enferm USP 2017;51:e03251. http://dx.doi.org/10.1590/S1980220X2016048803251 